muscular weakness and atrophy may result' is surely a fallacy perpetuated from older text books. On page 162 it is stated that benign positional nystagmus 'results from a degenerative lesion', but there is no mention of either examples due to head injury or to chronic suppurative otitis media. One would also dispute the statement on page 432 that the side effects of L-dopa are reduced when combined with a decarboxylase inhibitor. Misprints are few, though there is one (asphasia) on the first page of the preface. One delicious misprint might almost have been intentional, 'The hallucinations induced by mescaline and LSE (sic) are often terrifying and rarely pleasurable'.

These minor criticisms by no means detract from an excellent book which in covering the Essentials of Neurology must surely be essential reading for MRCP and can be read with advantage by all practising physicians.

\section{Essentials of Respiratory Disease}

By R. B. Cole (2nd edition). Pp. viii +297 , illustrated, soft cover. Pitman Medical: Tunbridge Wells, Kent, 1975. $£ 5.00$.

This remarkable book deserves to be in the possession of every student and every qualified doctor. It is a masterpiece of condensation and of accurate factual information, with a full bibliography for subsequent reading. Now appearing in its second edition, it is likely to see many more.

Dr R. B. Cole has shouldered the whole burden of putting it together himself and, although he is at pains to thank his assistants, it remains a 'single-author' work. The number of medical books written by one author is becoming fewer and fewer, owing to the increasing complexity of medicine-but those that do appear are increasingly precise, and the medical public is fortunate that this author has the energy, the authority and the clarity of expression to produce for us a homogeneous work of such value.

\section{Hemorrhage in Leukemias}

By Jerzy Lisiewicz. Pp. 226, illustrated, hard cover. Warsaw: Polish Medical Publishers, 1976. \$8.25.

The author has selected the topic of haemorrhage in leukaemia for a 200 page monograph. While nobody will disagree about the great importance of the topic as part of the overall clinical problem of the management of leukaemia and about the complexities of the mechanisms involved, the topic is discussed out of context of the disease. This tends to make the text rather unreal.

The first section is a fairly orthodox account of current ideas on haemostasis, although the account of disseminated intravascular coagulation is less convincing. Then follows a detailed if rather uncritical review of the literature in relation to haemostasis in each of the leukaemias. There is even a sixteen page account of haemostasis in eosinophilic leukaemia.

This book may well serve as a source of reference on this aspect of leukaemia and in particular to the contributions made by our continental colleagues. It does not deal with the management of bleeding problems in leukaemia. It will prove of interest to those working in this field.
Recent Advances in Clinical Psychiatry Number 2

Edited by Kenneth Granville-Grossman. Pp. viii +358 , hard cover, illustrated. Edinburgh: Churchill Livingstone, 1976. $£ 12.00$.

It is rare to find a book on psychiatry of such high quality as this. The eleven authors have been widely chosen and have each delivered an authoritative up-to-date statement of the body of knowledge in their respective fields. There is little in the way of pontification and sabre rattling. The best service this reviewer can do with his available space is to list the contents:

Clinical Psychopharmacology, Malcolm Lader

Drug Treatment, Maurice Lipsedge

The Depressions and Neurosis of Later Life, D. W. K. Kay

The Theory and Measurement of Personal Constructs, Fay Fransella

Social Factors in Mental Illness, Jacqueline Grad de Alarcón

Differential Aspects of Psychiatry in the Female, C. M. Tonks

Behavioural Treatments in Psychiatry, Michael J. Crowe

Marital Breakdown: Epidemiology and Psychotherapy, Sidney Crown

Neurosurgical Treatment of Psychiatric Disorders, Desmond Kelly

Epilepsy and Psychopathology, P. Flor-Henry

Child Psychiatry, Israel Kolvin and Angus Macmillan

There is no pretext that the volume provides a complete coverage of recent developments and the result is a manageable, readable book. The printing and general presentation are good. The Editor, who has modestly stayed in the background, is to be congratulated.

\section{Understanding EEG}

By Donald Scotr. Pp. xiii +248 , soft cover, illustrated London: Duckworth, 1976. £3.95.

Until now, the EEG literature has included a large didactic volume known to aficionados as 'The Bible', and a handful of smaller books filled with illustrations of EEG records and rather dry commentary. Now, Dr Scott, fresh from his triumph in writing a deservedly popular book 'About Epilepsy', has written a book 'Understanding EEG', that should have a wide appeal. It is aimed at senior medical students, postgraduates in medicine, surgery and anaesthetics, as well as electrophysiological technicians and also at General Practitioners and others who receive EEG reports from hospitals.

After an opening chapter entitled 'What Happens in the EEG Department', there are chapters on the normal and abnormal EEG, epilepsy, cerebrovascular disease, tumours and head injuries. The special problems of neonates and children are discussed separately and there are also topical chapters on sleep, brain 'death', anaesthetics and the EEG, as well as the problems and future of EEG and a particularly valuable section on the EEG report.

It is beautifully written, easy to read, informative and even provocative and could be said to contain in the format of a 200-page paperback plus glossary and bibliography 'all you need to know about EEG but never thought to ask'. At $£ 3.95$, it should be regarded as a snip and is warmly recommended 